\title{
O PROGRAMA ESCREVENDO O FUTURO E AS AÇÕES DA OLIMPÍADA DE LÍNGUA PORTUGUESA NA FORMAÇÃO CONTINUADA DE PROFESSORES
}

\author{
The "Escrevendo o Futuro" (Writing the Future) Program and the Actions of the \\ Portuguese Language Olympics on Continued Teacher Education
}

Míriam Fernanda Costa ${ }^{1}$

\begin{abstract}
Resumo: Este trabalho tem como propósito apresentar uma análise do Programa Escrevendo o Futuro no que se refere a algumas de suas dinâmicas como ações formativas. Busca-se identificar ações de formação de professores do Escrevendo o Futuro Olimpíadas de Língua Portuguesa através da identificação de suas características, com o intuito de analisar uma das ações do programa, juntamente com a conceituação do que a configura como ação formativa. Para nortear a análise, tem-se a seguinte questão: Que características, propostas ou recursos estão presentes no Escrevendo o Futuro que o faz assumir uma perspectiva formativa para professores? A presente pesquisa baseou na revisão bibliográfica, tomando como ponto de partida o portal do Escrevendo o Futuro em diálogo com autores que discutem formação de professores e linguagem, tais como: Bakhtin (2003), Gatti (2010), Nóvoa (2017), Signorelli (2016), Silva (2016), entre outros. Os resultados vêm apontando que o Programa Escrevendo o Futuro se caracteriza como uma ação formativa para os docentes, pois oferece a eles um espaço de se autoformarem e aprimorarem seus conhecimentos. Nota-se que ele também assegura um espaço para que os professores possam relatar suas práticas escolares, com circulação e reconhecimento do saber construído no interior das escolas, possibilitando que este contribua de forma direta ou indireta para a formação dos seus pares. Conclui-se, assim, que o Escrevendo o Futuro pode ser visto como uma oportunidade de aperfeiçoamento profissional, de troca de experiências de ensino e também de valorização da voz docente.
\end{abstract}

Palavras-chave: Escrevendo o Futuro. Formação de professores. Relato de prática.

Abstract: The purpose of this study is to present an analysis of the "Escrevendo o Futuro" (Writing the Future) Program in terms of some of its dynamics as formative actions. We seek to identify teacher education/training actions in the "Writing the Future" Portuguese Language Olympics by identifying its characteristics in order to analyze one of the program's actions, together with the conceptualization of what makes it a formative action. To guide the analysis, there is the following question: What characteristics, proposals or resources are present in the "Writing the Future" Program that make it take a formative perspective for teachers? This research was based on literature review by having the "Writing the Future" website as its starting point in a dialogue with authors who discuss teacher education and language, such as Bakhtin (2003), Gatti (2010), Nóvoa (2017), Signorelli (2016), Silva (2016), among others. The results have shown that the "Writing the Future" Program is characterized as a formative action for teachers, as it provides them a space to self-train and improve their knowledge. It also ensures a space for teachers to report on their school practices, with circulation and recognition

\footnotetext{
${ }^{1}$ Mestra em Educação pela Universidade Federal de Juiz de Fora (UFJF). Professora da Educação Básica na Rede Municipal de Ensino de Juiz de Fora e pesquisadora voluntária do Grupo Interação, Sociedade e Educação (CNPq/UFJF). ORCID: https://orcid.org/0000-0001-8989-2591. E-mail: miriamfernandajf@ yahoo.com.br.
} 
of knowledge built within schools, enabling it to contribute directly or indirectly to the formation of their peers. It is therefore concluded that the "Writing the Future" Program can be seen as an opportunity for professional improvement, to exchange teaching experiences and to value the teacher's voice.

Keywords: Writing the Future. Teacher training. Practice report.

\section{Introdução}

O Programa Escrevendo o Futuro foi criado em 2002 pela Fundação Itaú Social em parceria com o Centro de Estudos e Pesquisas em Educação, Cultura e Ação Comunitária (Cenpec), Conselho Nacional de Secretários de Educação (Consed) e União Nacional dos Dirigentes Municipais de Educação (Undime). Mas somente no ano de 2008 ele se torna uma política pública, ao fazer parceria com o Ministério da Educação (MEC) na realização da Olimpíada de Língua Portuguesa Escrevendo o Futuro. No portal do programa, estão presentes diversas ações que permitem a formação do professor, sendo a Olimpíada de Língua Portuguesa Escrevendo o Futuro, por exemplo, uma delas.

A escolha por esta investigação surgiu, primeiramente, da minha inserção como professora nas escolas, pois ouvia docentes comentando sobre o programa pelos corredores e sala de professores de modo recorrente. A partir desta curiosidade, cadastrei-me no Escrevendo o Futuro e comecei a navegar pelas abas da plataforma, baixar alguns textos, assistir aos vídeos e ler os materiais disponíveis ali mesmo no portal. Percebi que ele apresentava uma concepção de linguagem sociodiscursiva, ancorada na concepção de linguagem bakhtiniana, o que me fez tomá-lo como objeto para este estudo. Outro fator que também despertou o interesse pelo Escrevendo o Futuro foi a forma da sua apresentação, com indícios de ser um espaço formativo bem interessante para o professor.

Com base nisso, levantamos a seguinte questão: Que características, propostas ou recursos estão presentes no Escrevendo o Futuro que o faz assumir uma perspectiva formativa para professores? Para responder à questão levantada, o presente trabalho apresenta como objetivos: i) Identificar algumas ações de formação de professores do Programa Escrevendo o Futuro Olimpíada de Língua Portuguesa; ii) Apresentar quais são as suas características e iii) Analisar uma das ações de formação do programa.

Como metodologia para este estudo, foi realizada uma pesquisa de revisão bibliográfica de caráter qualitativo, tomando-se como ponto de partida o Programa Escrevendo o Futuro em diálogo com autores que discutem formação de professores e linguagem, tais como: Bakhtin (2003), Gatti (2010), Nóvoa (2017), Signorelli (2016), Silva (2016), entre outros.

Para este texto, foram selecionadas algumas ações que estão inseridas em dois eixos do programa (formação e recursos), justamente por fazerem um diálogo bem direto com a formação docente pelo viés da escrita e da linguagem. Buscaremos focar, principalmente, no eixo de formação, destacando os relatos de práticas que se fazem presentes no referido eixo, até mesmo porque são diversas as ações presentes no programa.

Este trabalho está organizado da seguinte forma: além desta introdução, a segunda seção abordará a formação de professores e se desdobrará nas subseções "O processo de formação do professor: o acesso aos letramentos" e "Formar pela linguagem"; na terceira seção, será apresentado o Programa Olimpíada de Língua Portuguesa Escrevendo o Futuro e algumas de suas ações; posteriormente, há a seção "O relato de experiência: uma ação presente no 
programa". Logo após, na quarta seção, será exposta a Metodologia, e na quinta seção, serão realizadas as análises. Por fim, tecemos as considerações finais e apresentamos as referências.

\section{Formação de professores}

De acordo com a resolução $\mathrm{n}^{\circ} 2$, de $1^{\circ}$ de julho de 2015 , é fundamental a formação dos profissionais do magistério para o sistema educacional do país, coisa que até pouco tempo não era vista desta forma. Gatti (2010) salienta que a profissão docente já foi exercida por qualquer pessoa considerada autodidata, ou seja, sem nenhuma formação específica. A exigência de uma formação para atuar na profissão docente se consolidou somente a partir da Lei de Diretrizes e Bases (LDB) - Lei 9394/96, quando o ensino superior passou a ser uma premissa para formação desses profissionais. Dessa forma, consideramos que:

[...] a formação inicial de professores é influenciada por inúmeros fatores e, dada a sua complexidade, faz-se necessário [...] que as atividades não visem somente ao domínio do conhecimento teórico (o saber), como também ao saber - fazer, oferecendo aos futuros profissionais condições de trabalho para o poder fazer (ARAÚJO, 2014, p. 260 - grifo da autora).

Sustentando o que foi posto por Araújo (2014), o domínio da teoria, por si só, não garante, ou melhor, não assegura que o indivíduo saiba fazer na prática. Por isso, Gatti (2010, p. 1360) aponta que "[...] não há consistência em uma profissionalização sem a constituição de uma base sólida de conhecimentos e formas de ação", para isso, acrescenta a referida autora que é necessária uma verdadeira revolução nas estruturas institucionais formativas e nos currículos.

Nóvoa (2017) nos aponta que para pensar a formação docente é preciso vê-la como formação profissional, ou seja, é de suma importância trazer para dentro dos espaços formativos aspectos que de fato contribuam para formação e atuação profissional. Por vezes, de acordo com Nóvoa (2017), o curso de formação de professor não tem seu foco para atuação profissional, assim como também revelam pesquisas realizadas por Gatti (2010). Para a autora, a formação de professores precisa partir da prática e juntamente a ela os conhecimentos teóricos que são eleitos como necessários, pois, afinal, trata-se de uma formação para atuação em contextos educacionais. Porém, pesquisas desenvolvidas por Gatti (2010) vêm apontando que os cursos não se configuram desta forma, pelo contrário, pois:

\footnotetext{
O grupo 'Didáticas Específicas, Metodologias e Práticas de Ensino' (o "como" ensinar) representa $20,7 \%$ do conjunto, e $7,5 \%$ das disciplinas são destinadas aos conteúdos a serem ensinados nas séries iniciais do ensino fundamental, ou seja, ao "o que" ensinar. Esse dado torna evidente como os conteúdos específicos das disciplinas a serem ministradas em sala de aula não são objeto dos cursos de formação inicial do professor. Disciplinas relativas ao ofício docente representam apenas $0.6 \%$ desse conjunto (GATTI, 2010, p. 1375).
}

Em consonância com Araújo (2014), Nóvoa (2017) e Gatti (2010), Clot (2006) nos aponta que, se forem oferecidas nos cursos de formação possibilidades de práticas que permitam os futuros professores se apropriarem, refletirem e se confrontarem perante as atividades que lhes são propostas no contexto formativo, isto beneficiará a este futuro profissional a pensar sobre os embates que ele poderá encontrar no contexto de sala de aula com seus alunos. Por 
isso, a formação inicial precisa ter como propósito a intenção de oportunizar aos alunos conhecimentos que sejam imprescindíveis para a docência (SIGNORELLI, 2016).

Também para Nóvoa (2017), a formação docente precisa ser diretamente influenciada pela 'dimensão profissional', não apenas no sentido técnico, mas sim concebendo-a como profissão. Para isso, é preciso "[...] promover uma formação docente que possibilite ao professor apropriar-se de ferramentas para agir nesse novo contexto de ensino e, com isso, tenha condições de tornar-se ator do seu fazer profissional", como aponta Barros (2012, p. 20). Essa compreensão de formação desafia a todo o momento os espaços formativos a se articularem e se movimentarem para atenderem às demandas atuais.

Sendo assim, são imprescindíveis, no processo de formação do professor, atividades que favoreçam o acesso aos letramentos múltiplos, assim como também se torna fundamental ter clareza dos processos de escrita, para que as práticas de escrita contribuam para a atuação profissional.

\subsection{O processo de formação do professor: o acesso aos letramentos}

Contemporaneamente, a escrita se faz presente a todo o momento nas sociedades urbanas mais modernas, seja ela em formas mais simples de representação ou em formas mais complexas. Então deve ser perguntado: Qual é o sentido da escrita? Por que escrever? Se, ao iniciar esse processo, todos pudessem entender o motivo para o qual se escreve, a escrita teria um significado maior e, consequentemente, uma reflexão mais profunda sobre o seu uso. Atualmente, aquele que não tem um conhecimento mais amplo da escrita e do seu sistema ou, ainda, aquele que sequer é alfabetizado, é discriminado, marginalizado e descartado do seu contexto social, principalmente daqueles nos quais exigem-se formas de escrita mais sofisticadas.

Vivemos em uma sociedade da escrita, em que saber apenas ler e escrever não basta. É preciso saber fazer uso da leitura e da escrita, reconhecer seus significados em seus diversos contextos, utilizando-as como ferramentas de prática e de interação social. E não apenas como sistema de signos, como aponta Bakhtin (2003). Na docência, “[...] o ato de escrever e ler o escrito de forma reflexiva permite ao professor ver a realidade de sua ação com maior objetividade e, assim, estabelecer conexões entre teoria e prática, aspecto que habilita o professor a tomar decisões" (SIGNORELLI, 2016, p. 126).

O motivo de escrever é o de expressar um sentimento, um conhecimento, um pensamento, uma ideia, assim como também uma reflexão sobre determinado assunto ou experiência vivida. A escrita sobre o que é vivenciado para o professor, nesta perspectiva, é uma "[...] maneira de aprender a atividade profissional, pela reflexão, pois permite atribuir significados à ação e construir conhecimentos necessários à docência”, destaca Signorelli (2016, p. 131). É também um modo de comunicação, interação e persuasão que envolve não somente o interlocutor e a mensagem que precisa ser entendida, mas trata-se de um conjunto de ideias e de valores a serem transmitidos.

A escrita possibilita a interação entre os membros da sociedade, ou seja, é a partir da palavra escrita que a comunicação e a interação se tornam possíveis. Com relação a essa interação, Bakhtin (2003, p. 117) afirma que:

\footnotetext{
Essa orientação da palavra em função do interlocutor tem uma importância muito grande. Na realidade, toda palavra comporta duas faces. Ela é determinada tanto pelo fato de que procede de alguém, como pelo fato de que se dirige para alguém. Ela constitui justamente o produto de interação do locutor e do ouvinte. Toda palavra serve de expressão a um em relação ao outro [...].
} 
O uso e a função da escrita se fundamentam em permitir o acesso do indivíduo a outros mundos, tais como o da mídia, os de domínio público, os burocráticos, os políticos, os jurídicos, os tecnológicos, os institucionais, dentre outros. Afinal, a escrita tem uma função importante na interação social, pois ela, segundo Catani et al. (2000) apud Signorelli (2016, p. 126), é “[...] uma forma de expressão e de objetivação do pensamento que possibilita ao sujeito reforçar ou constituir sua consciência a respeito daquilo que escreve [...]".

Assis et al. (2015) ressaltam que não basta apenas saber escrever e ler em situações diversas do cotidiano, mas sim saber agir e pensar por meio dela. Corroborando Assis et al. (2015), os Parâmetros Curriculares Nacionais de Língua Portuguesa - PCN's - LP (BRASIL, 1997) e a Base Nacional Comum Curricular - BNCC (BRASIL, 2017) apontam que os campos da escrita e da leitura são importantes, pois através dessas competências, os indivíduos se comunicam, assim como também se colocam perante a sociedade, apresentando e defendendo os seus interesses e atuando, desse modo, como sujeitos.

Portanto, infere-se que, no meio acadêmico, deve haver espaços e situações de aprendizagem que possibilitem as experimentações dos alunos nas diversas práticas de escrita e também de leitura. Para tal, deve ser levado em consideração, conforme destaca Street (2014), que não há letramentos superiores ou inferiores uns aos outros, ou que existam letramentos melhores ou piores, bons ou ruins; é fato que o que ocorre é a convergência de uma diversidade de letramentos, em que se destacam os níveis de letramentos, em que o grau de valor irá depender do contexto interacional em que ele se encontra. Portanto, todas as formas de letramentos são importantes nas práticas letradas, segundo afirma Street (2014). Kleiman (2007) aponta, conclusivamente, sobre essa relação entre letramentos, professor, ensino e aluno:

\begin{abstract}
Assim, o professor que adotar a prática social como princípio organizador do ensino enfrentará a complexa tarefa de determinar quais são essas práticas significativas e, conseqüentemente, o que é um texto significativo para a comunidade. A atividade é complexa porque ela envolve partir da bagagem cultural diversificada dos alunos que, antes de entrarem na escola, já são participantes de atividades corriqueiras de grupos que, central ou perifericamente, com diferentes graus e modos de participação (mais autônomo, diversificado, prestigiado ou não), já pertencem a uma sociedade tecnologizada e letrada (KLEIMAN, 2007, p. 9).
\end{abstract}

Nessa perspectiva, a formação acadêmica, segundo Street (2014), pode ser mais significativa se for realizada a junção do letramento vernacular com o dominante, pois a boa formação acadêmica é necessária, mas não podem deixar de serem considerados os letramentos, os conhecimentos que o aluno construiu antes de entrar na universidade, antes de ter contato com a esfera acadêmica. Por isso, é fundamental ao professor universitário - principalmente os professores universitários que atuam em cursos de licenciatura -, que contribui para formar outros professores, colaborar sobremaneira para um ensino que valorize o real objetivo da leitura e da escrita em sala de aula, em suas múltiplas faces, e não apenas tratar das técnicas para que os universitários sejam capazes de realizar algumas limitadas formas de ler e escrever.

Para tudo isso, se faz necessário contemplar os letramentos, pois sabemos que as atividades humanas são variadas e as práticas sociais que envolvem o uso da escrita e da leitura também o são, fazendo-nos refletir que não há um letramento, mas vários letramentos. Assim, o letramento que se aprende na escola é apenas um dos letramentos em meio a vários outros. Por isso, a tendência de usar essa palavra no plural. 
Nessa construção de ideias, vale frisar que "Um dos objetivos da escola é justamente possibilitar que seus alunos possam participar de várias práticas sociais que se utilizam da leitura e da escrita (letramentos) na vida da cidade, de maneira ética, crítica e democrática" (ROJO, 2009, p. 107 - grifo da autora). Então, faz-se necessária a reflexão de que não há apenas um letramento, mas letramentos, porque variados também são os fatores sociais, culturais, tecnológicos e históricos.

É com base nessas novas e múltiplas formas de organização e de participação social que surgem as variações de letramentos que se ramificam nas práticas sociais contemporâneas reais ou virtuais - em sua multiplicidade (letramentos múltiplos) (ROJO, 2009), relacionados com a cultura local dos sujeitos (letramento vernacular), com os letramentos valorizados universal e institucionalmente (letramentos ideológicos e dominantes); a partir dos letramentos multissemióticos "[...] exigidos pelos textos contemporâneos, ampliando a noção de letramento para o campo da imagem, da música, das outras semioses que não somente a escrita [...]" (ROJO, 2009, p. 107); os letramentos críticos e protagonistas, promovidos pelos tantos textos que circulam na sociedade e selecionados a partir das escolhas éticas, políticas, ideológicas, em que o leitor "[...] não pode lidar com eles de maneira instantânea, amorfa e alienada" (ROJO, 2009 , p. 108); os letramentos digitais que correspondem a "[...] habilidades individuais e sociais necessárias para interpretar, administrar, compartilhar e criar sentido eficazmente no âmbito crescente dos canais de comunicação digital" (DUDENEY; HOCKLY; PEGRUN, 2016, p. 38); dentre tantos outros modos de letrar e de ser letrado.

A par de tantos modelos de letramentos como os citados por Rojo (2009) e Dudeney, Hockly, Pegrun (2016), é necessário que o professor planeje situações didáticas que proporcionem aos alunos criarem estratégias de escrita e leitura diversas para atender aos diferentes contextos, segundo os letramentos vigentes em cada caso. Dessa maneira, os professores, como agentes de letramento, têm a possibilidade de encontrar-se numa constante interação com seus alunos, para que estes tomem posse desse modo de ser e de estar neste novo universo. Assim, esses novos membros serão capazes de se apropriarem das práticas discursivas acadêmicas e as utilizarem na sua futura área profissional e também em possíveis atuações no campo da pesquisa.

Quando se faz uso da escrita e da leitura dentro da perspectiva dos letramentos, está havendo um exercício do conhecimento, destacam Assis et al. (2015), pois, segundo as autoras, a escrita se põe "[...] como meio de acesso aos saberes e como um modo de construção de saberes" (ASSIS et al., 2015, p.13). Assim, as práticas de escrita e de leitura precisam fomentar condições mais adequadas para a inserção dos professores no universo social e discursivo, tendo em vista a sua ação profissional. Isso precisa estar presente nos espaços de formação, seja ela inicial ou continuada, pois ler e escrever são grandes instrumentos de desenvolvimento e de apropriação de conhecimento, destacam Assis et al. (2015).

A linguagem assume a função de articular as várias práticas sociais presentes na sociedade por diferentes grupos, espaços e tempos nos quais os indivíduos estão inseridos por meio da escrita e da leitura, seja a partir de uma simples conversa num bar, uma lista de compras, um bilhete, um relato e até mesmo um artigo acadêmico.

Dessa forma, a formação pela linguagem proporcionará ao indivíduo se posicionar de maneira crítica e reflexiva como sujeito social. Sendo assim, o processo formativo para atuação docente precisa perpassar por uma abordagem crítica e reflexiva no que se refere aos usos sociais da linguagem para atender às necessidades da contemporaneidade. É a respeito da importância da formação pela linguagem que a seção a seguir discorrerá. 


\subsection{Formar pela linguagem}

De acordo com Magalhães, Garcia-Reis e Ferreira (2017), o processo formativo para a atuação docente precisa perpassar por uma abordagem crítica e reflexiva ao se referir aos usos sociais da linguagem. As autoras reconhecem a linguagem como prática social e dialógica, ou seja, numa dimensão discursiva, a qual segundo elas se caracteriza pela peculiaridade que assume no uso e nos contextos sociais que a linguagem se manifesta. Portanto, a linguagem precisa ser concebida em sua plenitude, como algo essencial à vida humana, pois para Bakhtin (2003) a linguagem é essencialmente dialógica, sendo esse o princípio constitutivo e organizador da mesma. Do ponto de vista bakhtiniano, a linguagem se constrói por meio do diálogo entre sujeitos em contextos reais, sendo então essencialmente dialógica, pois

[...] em qualquer enunciado, quando estudado com mais profundidade em situações concretas de comunicação discursiva, descobrimos toda uma série de palavras do outro semilatentes, de diferentes graus de alteridade. Por isso o enunciado é representado por ecos como que distantes e mal percebidos das alternâncias dos sujeitos do discurso e pelas tonalidades dialógicas, enfraquecidas ao extremo pelos limites dos enunciados, totalmente permeáveis à expressão do autor (BAKHTIN, 2003, p. 299).

Nessa perspectiva, a interação é uma fonte essencial da linguagem, pois todo discurso é formado por diversas vozes sociais. Desse modo, o dialogismo nos leva a perceber que a linguagem se constitui por meio de interlocutores reais em contextos sociais, que estão envoltos por diferentes vozes ideológicas; desta maneira podemos entender a linguagem sob a perspectiva sociodiscursiva. De acordo com a teoria bakhtiniana, o discurso é mediado por uma natureza dialógica, quando ele é visto como cerne da linguagem. Sendo assim, na perspectiva teórica assumida neste texto, em diálogo com o que postula Vygotsky, a linguagem "[...] atuaria não só como um elemento mediador entre nós e o mundo, mas mais que isso, ela é a própria mediação, uma vez que possibilita a mediação entre os sujeitos e os significados já constituídos socialmente" (CADILHE; GARCIA-REIS, 2017, p. 219).

Compreendemos, como aponta Bakhtin (2003), que a linguagem é fundamental nas atividades sociais e que, além disso, ela assume um papel importante no desenvolvimento humano, conforme já destacado anteriormente. Dessa forma, agir pela linguagem é "[...] agir a partir de uma determinada motivação, muito contextualizada pelos apontamentos da situação de comunicação em questão" (GARCIA-REIS; COSTA, 2018, p. 4). Uma vez assumida a concepção discursiva da linguagem, a formação de professores precisa passar por tal aspecto para que assim este futuro professor possa atuar em suas atividades profissionais na mesma perspectiva da qual foi formado, ressalta Cadilhe; Garcia-Reis (2017). Pois como professores que não passaram por tal formação desenvolverão práticas de linguagem nessa perspectiva?

Ao observar a perspectiva dialógica apontada por Bakhtin (2003) e tomando o ambiente formativo como foco deste estudo, partimos do pressuposto de que ao produzir um texto, estamos estabelecendo um diálogo com outros textos e produzindo discursos com outras pessoas. Porém, este diálogo só será possível a partir dos nossos conhecimentos (letramentos) e do domínio dos gêneros do discurso que estão presentes nos diversos contextos. Para Bakhtin (2003):

Os gêneros do discurso organizam o nosso discurso quase da mesma forma que o organizam as formas gramaticais (sintáticas). Nós aprendemos a moldar o nosso discurso em forma de gênero e, quando ouvimos o discurso alheio, já adivinhamos o seu gênero pelas primeiras palavras, adivinhamos um determinado volume (isto é, 
uma extensão aproximada do conjunto do discurso), uma determinada construção composicional, prevemos o fim, isto é, desde o início temos a sensação do conjunto do discurso que em seguida apenas se diferencia no processo da fala. Se os gêneros do discurso não existissem e nós não o dominássemos, se tivéssemos que criá-los pela primeira vez no processo de discurso, de construir livremente e pela primeira vez cada enunciado, a comunicação discursiva seria quase impossível (BAKHTIN, 2003, p. 283).

Dessa forma, ao tomar como referência a posição do Círculo de Bakhtin, compreendemos a linguagem como algo essencialmente construída pelas práticas sociais, assim, podemos dizer que a comunicação só é possível por meio da linguagem.

\section{O Programa Olimpíada de Língua Portuguesa Escrevendo o Futuro e algumas de suas ações}

O Programa Escrevendo o Futuro foi criado no ano de 2002 pela Fundação Itaú Social, com coordenação técnica do Centro de Estudos e Pesquisas em Educação, Cultura e Ação Comunitária (Cenpec), com o intuito de contribuir para a melhoria do ensino da leitura e escrita nas escolas públicas de todo território brasileiro. No ano de 2008, o Programa Escrevendo o Futuro torna-se uma política pública, por meio da parceria com o Ministério da Educação (MEC) e a realização da Olimpíada de Língua Portuguesa (OLPEF). O programa também conta com outras parcerias, como o Conselho Nacional dos Secretários de Educação (Consed), a União Nacional dos Dirigentes Municipais de Educação (Undime) e o Canal Futura.

O Programa Escrevendo o Futuro é um espaço para educadores, em que são disponibilizados materiais que contribuem para a inovação e o aprimoramento de conhecimentos e estratégias para o ensino de Língua Portuguesa. No Portal do programa, estão presentes diversas ações que propiciam a formação do professor, sendo a Olimpíada de Língua Portuguesa Escrevendo o Futuro, por exemplo, uma das ações, tendo como um de seus objetivos a formação de professores por meio de materiais orientadores, cursos presenciais e a distância e recursos didáticos para o desenvolvimento do trabalho em sala de aula.

Nos últimos anos, o Programa Escrevendo o Futuro vem desenvolvendo algumas ações e recursos formativos para docentes, numa perspectiva de formação continuada, propondo diversos espaços formativos, além da Olimpíada de Língua Portuguesa, como os apresentados nas abas do portal:' 'Formação' (cursos on-line, percursos formativos); 'Recursos' (cadernos virtuais, revistas e vídeos), entre outros, por exemplo, que colaboram com a formação do professor.

Vejamos em que consiste algumas dessas ações:

2 Para conhecer e se aprofundar mais nestas ações, visite o portal Escrevendo o Futuro: https://www.escrevendoofuturo.org.br/. 


\section{ifl:tear}

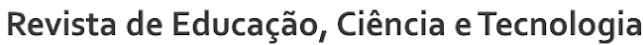

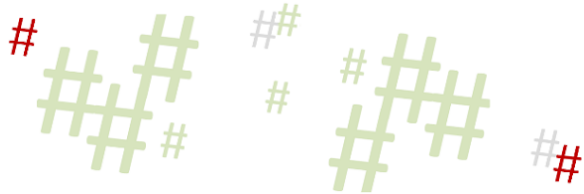

Figura 1- Cursos On-line
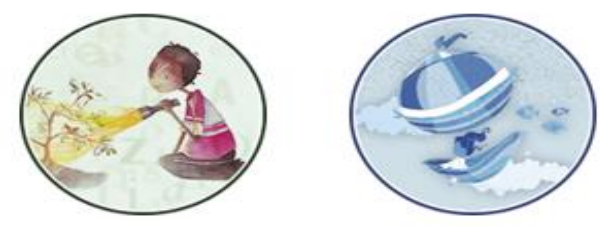

Caminhos da Escrita

Sequência

Didática:

aprendendo por

meio de resenhas

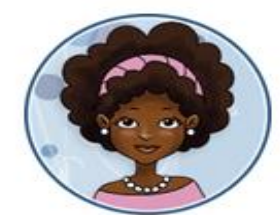

Avaliação Textual: análises e propostas

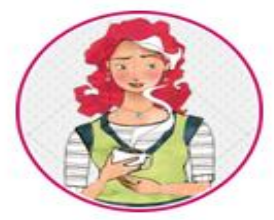

Nas tramas

do texto

Fonte: Escrevendo o Futuro (2019).

Figura 2- Literatura em Movimento
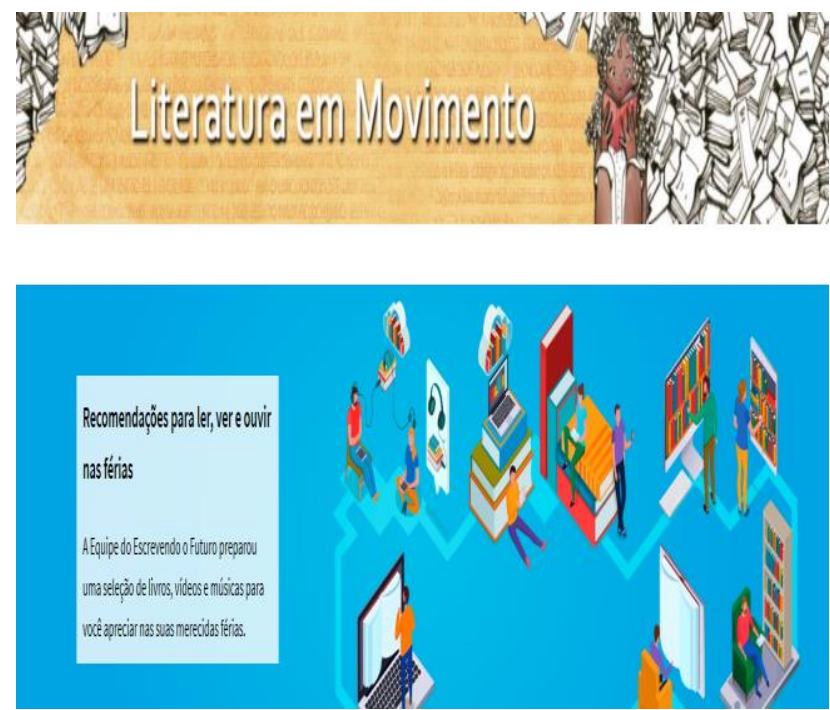

Fonte: Escrevendo o Futuro (2019).

A primeira ação que trouxemos são os Cursos On-line: "O Programa Escrevendo o Futuro oferece diferentes cursos a distância, para educadores de todo o Brasil. São cursos mediados e autoformativos, todos gratuitos e certificados, realizados por meio de um ambiente virtual de aprendizagem" (ESCREVENDO O FUTURO, 2021). Comungamos da ideia de Garcia-Reis (2019) e ressaltamos que esse tipo de ação tem grande relevância, pois além de fortalecer a atuação profissional do professor, enriquece também as atuações de ensino nas escolas, ou seja, é uma riquíssima ferramenta formativa. A segunda ação que citamos é Literatura em movimento. 
Trata-se de "Um espaço sobre literatura e ensino de leitura literária desenvolvido pelo Programa Escrevendo o Futuro com o objetivo de contribuir com os educadores de todo o Brasil. Lá você encontrará textos literários, entrevistas, artigos, reportagens, indicações de leituras e muitos outros materiais para ampliar sua prática docente" (ESCREVENDO O FUTURO, 2021).

Essa ação nos sinaliza que a leitura não pode ser apreendida apenas como a leitura do escrito, como decodificação de um código, como apontam Arruda; Teixeira; Barreiro (2015), mas necessita ser abordada e trabalhada pelas diversas linguagens presentes no cotidiano do leitor, seja por meio da decodificação de sinais gráficos, por meio de imagens estáticas ou em movimento, através de sinais do tempo ou de gestuais etc.

A terceira ação que apresentaremos são os Percursos Formativos:

Figura 3- Percursos Formativos

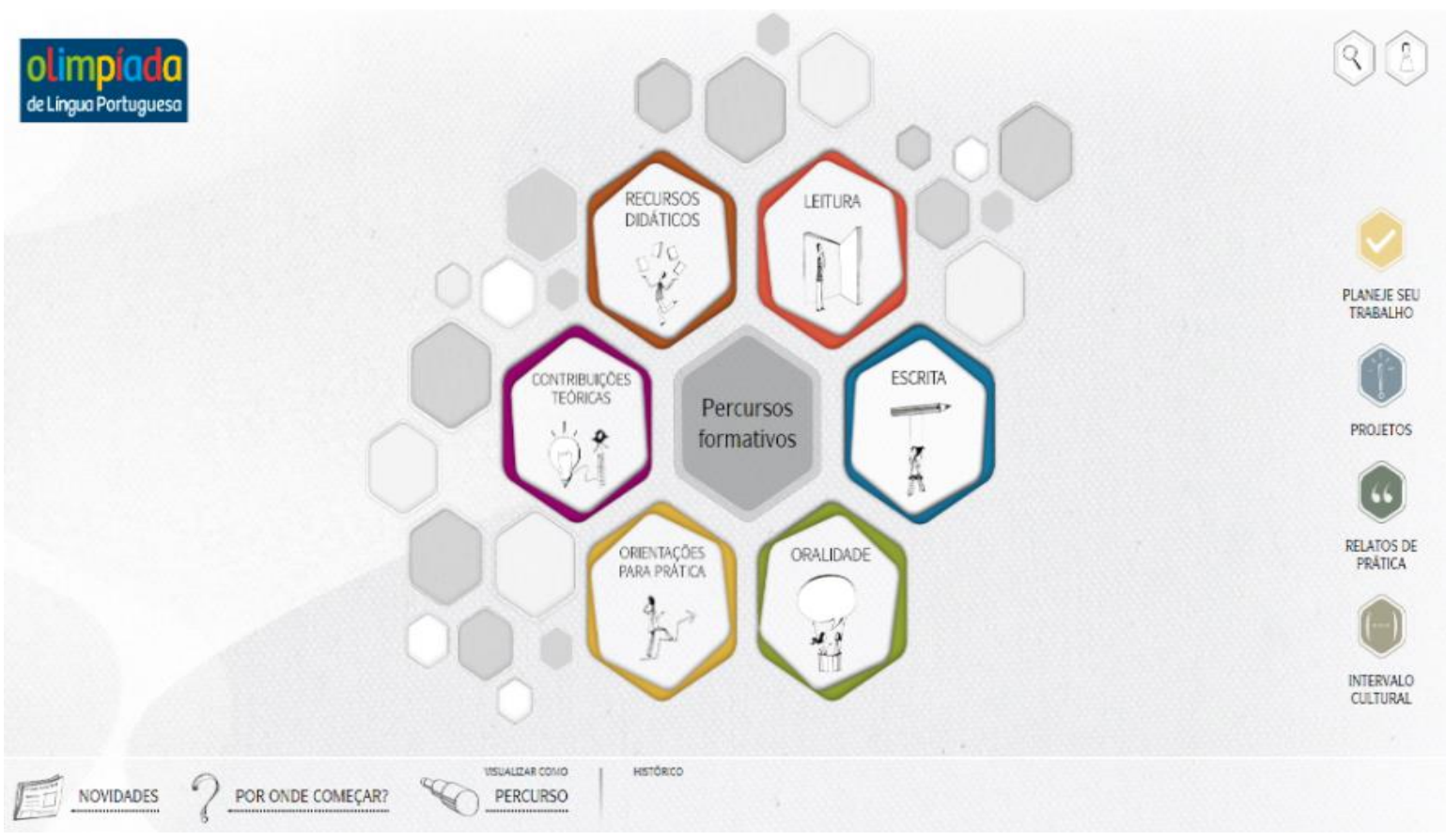

Fonte: Escrevendo o Futuro (2019).

Este é um:

[...] diagrama interativo que reúne conteúdos do Portal Escrevendo o Futuro e de outros sites relacionados, organizados em três eixos principais: escrita, leitura e oralidade. Em cada um deles, estão disponibilizados materiais de fundamentação teórica, orientações para a prática e de recursos didáticos para o trabalho em sala de aula. O educador é livre para criar seu próprio itinerário formativo, aprofundando-se nos temas nos quais tem maior interesse (ESCREVENDO O FUTURO, 2021).

Ao proporcionar ações formativas como essas, entre outras, o programa está promovendo ricos e frutuosos diálogos entre diferentes perspectivas e compreensões dos fenômenos educativos. As trocas de experiências proporcionadas pelos momentos de interatividade que o Escrevendo o Futuro oferece aos professores abarcam uma 

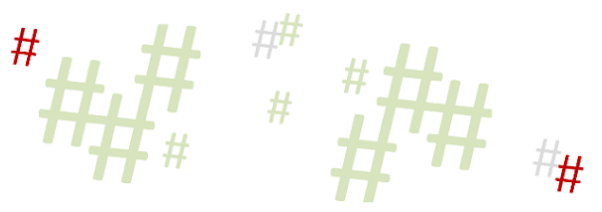

intencionalidade formativa que neste caso compreende-se como espaços "[...] que se protagonizam dessa forma e podem se transformar em lugares de formação e, com isso, amenizar a angústia provocada pelo isolamento, pela falta de apoio e de compartilhamento de saberes no cotidiano das escolas" (PASSOS, 2016, p. 165).

Considerando que os professores buscam por espaços de formação, eles demonstram interesse em ampliar o seu processo formativo em relação a sua profissionalização, pois, de acordo com Passos (2016, p. 169), esses professores são "[...] os que se interessam pela teoria, comparam seus trabalhos com os dos colegas, avaliam seu próprio trabalho e colaboram com os outros professores". Por meio das diversas ações que o programa oferece, o professor tem a possibilidade de desenvolver-se pessoal e profissionalmente e, além disso, compartilhar com seus pares os trabalhos que foram realizados em sala de aula, como por exemplo, por meio do relato de experiência.

A próxima seção abordará o relato de experiência, ou relato da prática: uma ação presente no programa, como processo de desenvolvimento e interação entre seus pares.

\subsection{O relato de experiência: uma ação presente no programa}

O professor, através deste programa, tem a chance de desenvolver suas capacidades reflexivas a partir do que realiza no seu contexto escolar, devido à possibilidade que tem de postar os relatos no portal, por exemplo. Silva (2016, p. 11) destaca que "As práticas de escrita e reflexão do professor são necessárias para a efetivação da articulação entre saberes teóricos e práticos [...]" e para isso pode-se contar com o gênero relato de experiência que é uma das maneiras de dar voz ao sujeito. Ainda, de acordo com Garcia-Reis (2019), ancorada em Vigotsky (2010), as possibilidades de aprendizagem e desenvolvimento, sejam sociais, psíquicos ou profissionais, são decorrentes de processos interacionais entre sujeitos em diferentes contextos formativos.

Dessa forma, “[...] Não é possível formar professores sem a presença de outros professores e sem a vivência das instituições escolares [...]" (NÓVOA, 2017, p. 1122). A partir dos relatos da prática que é uma das possibilidades de formação oferecida pelo programa, por exemplo, os professores têm a oportunidade de criar diálogos com seus pares e, além disso, divulgar suas práticas docentes. Segundo Garcia-Reis (2019), esse tipo de ação proporciona não somente o fortalecimento da atuação profissional, mas contribui diretamente e enriquece as atividades educacionais no contexto escolar. Ao relatar suas práticas de ensino, “[...] o professor tem a possibilidade de refletir sobre suas escolhas, de repensar sobre sua condição de ator nos processos formativos dos quais participa, conquistando novas aprendizagens e desenvolvendose profissionalmente" (GARCIA-REIS, 2019, p. 56).

Acreditamos que quando o professor tem a possibilidade de escrever sobre sua prática, ele se vê como protagonista na sua atividade, podendo refletir sobre ela e (re)significá-la. Garcia-Reis; Magalhães (2018) nos revelam que cada vez mais o uso do relato de experiência tem ganhado espaços nos contextos acadêmicos, justamente pelo potencial de transformação que esse gênero proporciona, tanto profissional quanto pessoalmente e, por isso, vem sendo solicitado cada vez mais em diversas instâncias. Os gêneros, de forma mais específica o gênero relato, conforme Micarello; Magalhães (2014, p. 160), "[...] são, então, uma forma de colocar a voz do sujeito no centro do processo de aprendizagem". É por meio da apropriação do gênero como instrumento que o sujeito se desenvolve, constrói e reconstrói significados para suas atividades. 


\section{Metodologia}

O Programa Escrevendo o Futuro é um espaço de formação para educadores, em que são disponibilizados materiais, metodologias e notícias que contribuem para a interação, inovação e o aprimoramento de conhecimentos e estratégias para o ensino de Língua Portuguesa, e, além disso, é um espaço no qual o professor pode compartilhar suas experiências e inspirar-se nas experiências de seus pares. A concepção de linguagem presente no Escrevendo o Futuro é sociodiscursiva, ancorada em Bakhtin, com base na prática de linguagem como uso e não apenas como sistema de signos, firmando-se a noção de discurso. É nessa perspectiva que este trabalho se respalda.

Falar da concepção de linguagem presente neste programa nos leva a inferir que a formação de professores precisa estar imbricada com práticas de linguagem dialógicas, as quais possibilitem experiências, pois é dessa maneira que o desenvolvimento profissional acontece.

A pesquisa está fundamentada na pesquisa bibliográfica, tendo como premissa o Programa Escrevendo o Futuro em diálogo com autores que discutem formação de professores e linguagem, tais como: Bakhtin (2003); Silva (2016); Gatti (2010); Micarello; Magalhães (2014); Garcia-Reis (2019); Garcia-Reis; Magalhães (2018); Nóvoa (2017); Signorelli (2016) entre outros, configurando-se como uma pesquisa de caráter qualitativo.

O objeto de análise é o Escrevendo o Futuro e algumas de suas ações, porém, será feito um recorte do relato de experiência, que se faz presente em uma das abas do portal. Após a breve apresentação da base teórica e do objeto de análise, o artigo tem como objetivos identificar algumas ações de formação de professores do Programa Escrevendo o Futuro Olimpíada de Língua Portuguesa, apresentar quais são suas características e analisar uma das ações de formação, que se configura como ação formativa.

\section{Analisando o relato de experiência}

Para esta análise, será feito o recorte em apenas uma das ações do programa, o relato de experiência, ou relato de prática, como é chamado pelo programa, visto que são diversas as ações.

Exemplo 1 - Fragmento do relato de prática: Refazendo a travessia

Autor: Regina Clara, NPL n ${ }^{\circ}$ 07, assunto: Relatos de Prática

É preciso acreditar no potencial dos alunos e oferecer a eles a oportunidade de explorar o desconhecido e de gostar do que ainda não gostam ou não conhecem. É preciso, sobretudo, buscar saídas quando o trabalho não flui e o processo de ensino e aprendizagem não avança. Isso é, em essência, o que esse relato nos diz. Vale a pena conhecer as soluções encontradas pela professora Regina Clara em sua travessia.

Professora relata a difícil experiência de trabalhar poesia com alunos desmotivados e com baixa auto-estima. Tarefa complicada, mas que teve seu lado poético, pois mesclou paciência, dúvidas e sofrimentos com novas descobertas, criação e a satisfação pela construção conjunta de saberes e novas sensibilidades.

Foi pensando nos acontecimentos que marcam o dia-a-dia em sala de aula, que voltei ao meu caderno de anotações para escrever este artigo e relatar a experiência do trabalho com poemas que realizei numa escola da capital paulista. Encontrei de tudo no caderno: reflexões, sentimentos, impressões e intercorrências próprias de cada uma das oficinas que realizei. São registros que ladeiam e bordam os cantos de cada ação planejada. 
Diante de tantas experiências, surgiu um dilema: que recorte fazer e o que selecionar, dentre as práticas, para narrar? Pensei nos leitores dessa publicação: em sua maioria, são professores como eu, que podem se identificar com o que tenho a dizer. Das histórias dessa travessia, entre ganhos e perdas, escolhi algumas passagens.

Fonte: Percursos Formativos (2019).

Vemos que, por meio desse pequeno fragmento, o interessante uso do relato da prática como ferramenta de autoformação proporcionou a professora Regina Clara refletir sobre a sua prática e o que poderia ser feito para mudar, perante o que ela tinha em seu contexto escolar. Kersch; Marques (2018, p. 92-93) destacam que "somente a sua passagem (a do professor) pela experiência permitirá que suas crenças, muitas vezes cristalizadas, possam ser ressignificadas e ele, de fato, queira mudar em sala de aula".

Foi a partir dos registros que ela teve a possibilidade de reconhecer e utilizar a escrita e a leitura como ferramenta de prática e de interação social, como aponta Bakhtin (2003). Além disso, ela faz reflexões sobre sua prática e do que é relevante trazer para ser apresentado a seus pares, pois a ação de escrever e ler o que foi escrito de maneira reflexiva proporciona ao professor ver a sua prática, ou melhor, a realidade com mais nitidez e ao mesmo tempo proporciona pensar sobre a teoria e a prática, como destaca Signorelli (2016).

Exemplo 2 - Fragmento do relato de prática

Figura 4 - Fragmento do relato de prática: Escrevendo na sala de aula - ponto de vista ${ }^{3}$

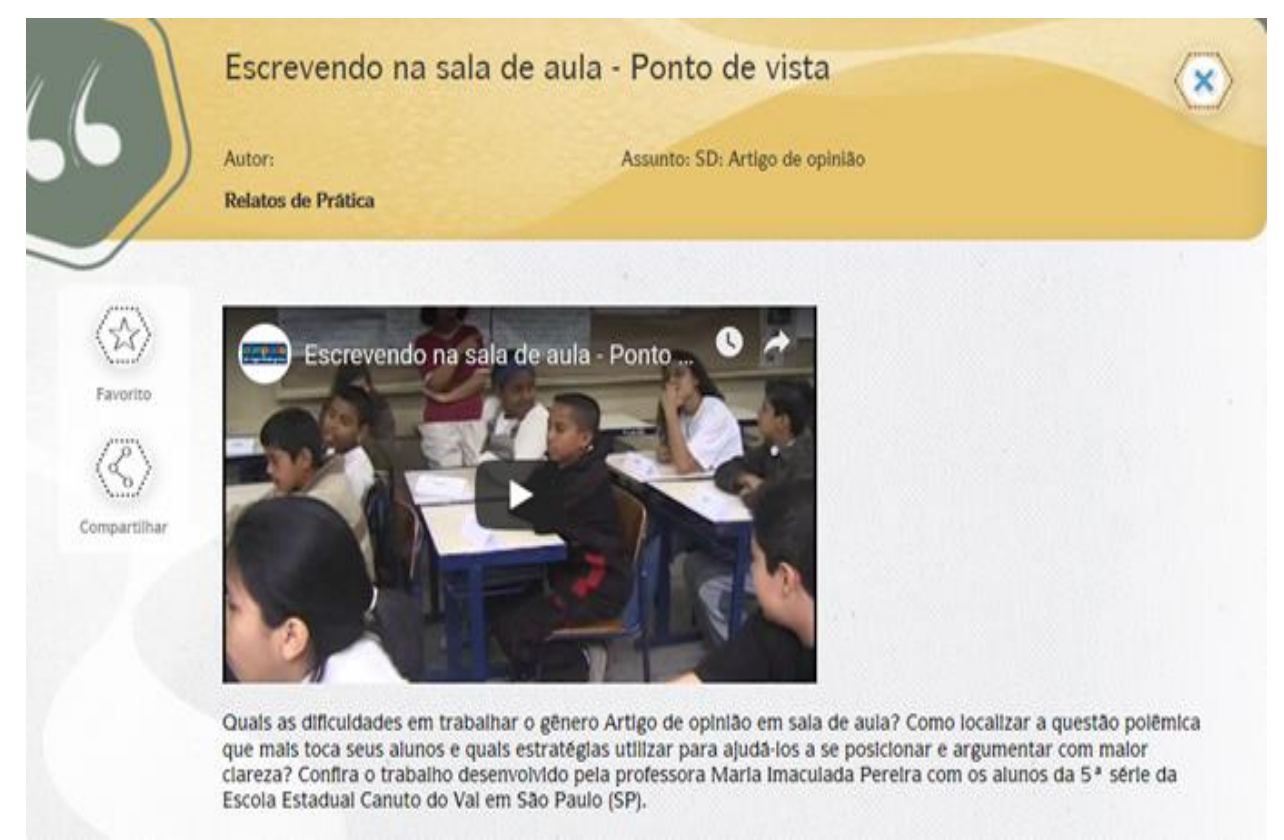

Fonte: Programa Escrevendo o Futuro (2019)

\footnotetext{
${ }^{3}$ Perguntas que foram feitas pela professora que estão presentes nesta imagem "Quais as dificuldades em trabalhar o gênero Artigo de opinião em sala de aula? Como localizar a questão polêmica que mais toca seus alunos e quais estratégias utilizar para ajudá-los a se posicionar e argumentar com maior clareza? Confira o trabalho desenvolvido pela professora Maria Imaculada Pereira com os alunos na $5^{\text {a }}$ série da Escola Estadual Canuto do Vai em São Paulo (SP)".
} 
O exemplo 2 exposto é outra possibilidade que o programa oferece aos professores para exibirem seus relatos: o relato em forma de vídeo. Para que o professor possa utilizar esse formato ao postar suas práticas, é necessário que faça uso das práticas digitais, ou seja, das de letramentos (ROJO, 2009; DUDENEY, HOCKLY, PEGRUN, 2016), como já exposto na seção 2.1 deste trabalho. Quantas vezes nos deparamos com perguntas como essas que a professora Maria Imaculada apresenta como mote para o seu relato? Com as questões postas, assim como Maria Imaculada, outros professores podem se identificar e, dessa maneira, considerar esse relato como fonte de formação para sua prática. Concebemos que

[...] o processo de aprendizagem está relacionado diretamente à participação social do sujeito, não apenas na sua responsabilidade e no seu compromisso com pessoas e atividades [...], mas na sua atitude ativa em práticas de comunidades sociais, onde aprende, interage e constrói sua identidade (KERSCH; MARQUES, 2018, p. 93).

Nesse sentido, o professor se torna interlocutor de discursos sobre a docência, ou seja, ele produz e lê discursos, e isso vai construindo e (re)construindo saberes sobre suas práticas, não somente para ele que produz o relato, mas também para seus pares.

Vejamos agora o exemplo 3:

Figura 5- Revista na ponta do lápis-Edição número 33, julho de 2019.

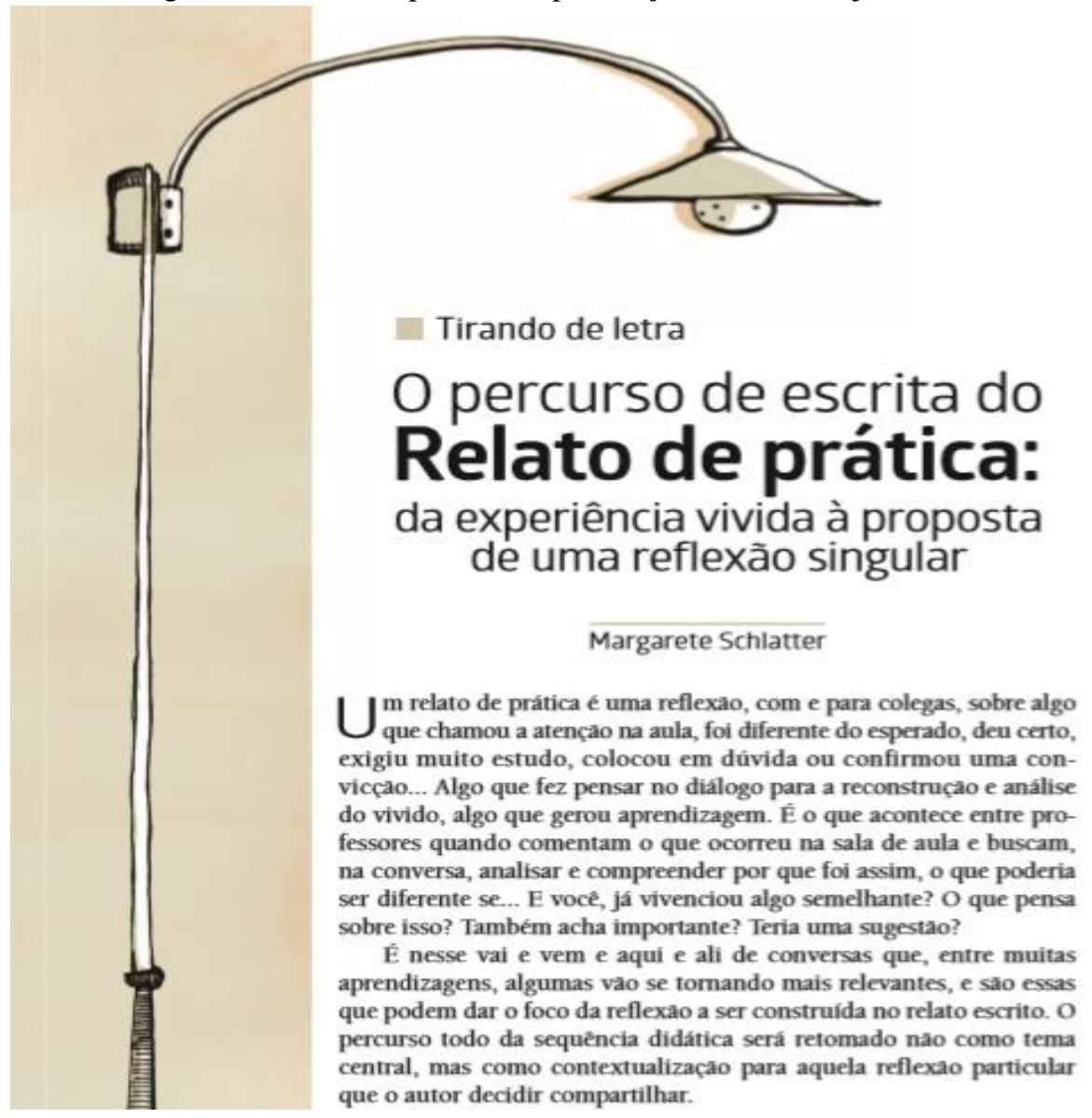

Fonte: Schlatter (2019, p. 26).

Aqui, encontramos outra oportunidade para o professor expor o seu relato de experiência, a 'Revista Na ponta do lápis', que faz parte dos recursos formativos do Programa 
Escrevendo o Futuro, o que vem reforçando que o programa acredita que quando o professor tem a possibilidade de escrever sobre sua prática ele pode (re)significá-la, pois possibilita várias maneiras de o professor exibir seus relatos, conforme apontado Garcia-Reis; Magalhães (2018). Sendo assim, "[...] promover atividades em colaboração criativa com textos, ferramentas e tecnologias midiáticas digitais é vital para dar sustentação ao desenvolvimento profissional do educador" (HOBBS; COIRO, 2016, p.1 apud KERSCH; MARQUES, 2018, p. 92).

Um outro aspecto relevante nos revela que cada vez mais o uso do relato de experiência tem ganhado espaços nos contextos acadêmicos, justamente por acreditar no potencial de transformação que esse gênero proporciona, tanto profissional quanto pessoalmente, por isso vem sendo solicitado cada vez mais em diversas instâncias, como afirmam Garcia-Reis; Magalhães (2018).

Logo, o aspecto formativo que os relatos assumem tem sido ressaltado por autores como Cunha (1997), pois ao mesmo tempo em que o professor organiza suas ideias para a escrita do relato, seja ele oral ou escrito, este está reconstruindo sua prática de forma reflexiva e, portanto, acaba fazendo uma autorreflexão que cria novas formas de compreender a sua própria prática. E, ainda, contribui direta ou indiretamente na formação de seus pares.

\section{Considerações finais}

Os resultados da investigação realizada apontam que a política de formação posta no Programa Escrevendo o Futuro se caracteriza como uma ação formativa para professores pela e para a linguagem, pois oferece um espaço de se autoformarem e aprimorarem seus conhecimentos, por meio da linguagem. O Escrevendo o Futuro é de grande importância, pois proporciona que professores compartilhem conhecimentos e troquem informações.

Constatamos que o professor, por meio do Escrevendo o Futuro, tem a oportunidade de desenvolver suas capacidades reflexivas entre os saberes práticos e teóricos, por meio dos percursos formativos, das ações e dos recursos que são disponibilizados. Salientamos que, quando um programa como este apresenta diversas ações que incitam o docente a pesquisar, questionar e buscar recursos para sua atuação no contexto escolar, ele permite ao professor não somente refletir sobre sua prática, mas vai além disso, quando oferece espaço para que relate sobre ela, construindo-se como sujeito deste processo. Assim, seja de forma direta ou indireta, incita seus pares a proporem práticas semelhantes ou até mesmo (re)significar suas atividades de sala de aula, o que consideramos altamente formativo.

Observamos que as ações do Escrevendo o Futuro possibilitam que os professores façam

parte dessa rede de conhecimentos, ao mesmo tempo em que ajudam a construí-lo. É perceptível que o programa tem a intencionalidade de promover a interação pela linguagem entre os profissionais da docência, pois têm a chance de desenvolver suas capacidades reflexivas por meio das relações e experiências vividas, através dos relatos.

Ponderamos também a importância dos letramentos que são adquiridos nos diversos espaços e situações, como pode ser observado nos exemplos apresentados no texto, pois são múltiplas as atividades humanas que exigem uma variedade de práticas sociais. Tendo em vista tantos modelos de letramentos, é necessário que o professor saiba planejar ações que atendam a diferentes contextos. Acreditamos que esta é também uma das intencionalidades do programa: mostrar a importância dos letramentos por meio das diversas ações que o constituem. Logo, o Programa Escrevendo o Futuro pode ser visto como uma oportunidade de aperfeiçoamento profissional, de troca de experiências de ensino e também de reconhecimento da voz do professor por meio das ações que ele oferece. 


\section{Referências}

ASSIS, Juliana Alves. "Eu sei mas não consigo colocar no papel aquilo que eu sei”: representações sobre os textos acadêmico-científicos. In: RINCK, Fanny; BOCH, Françoise; ASSIS, Juliana Alves. (org.). Letramento e formação universitária: formar para a escrita e pela escrita. Campinas, SP: Mercado das Letras, 2015.

ARAÚJO, Paula Francineti Ribeiro. Ensino de Língua Portuguesa: a transposição didática em questão. Eutomia. Recife, p. 240-262, dez, 2014.

ARRUDA, Janaina Rosa; TEIXEIRA, Fernanda Vaz Cordeiro Soares; BARREIROS, Ruth Ceccon. Memória de leitura: da graduação à prática docente. In: COSTA-HÜBES, Terezinha da Conceição; ROSA, Douglas Corrêa da. (org.). A pesquisa na educação básica: um olhar para a leitura, a escrita e os gêneros discursivos na sala de aula. Campinas, SP: Pontes, 2015, p. 97-118.

BAKHTIN, Mikael. Estética da Criação verbal. São Paulo: Martins Fontes, 2003.

BARROS, Eliana Merlin Deganutti. Gestos de ensinar e de aprender gêneros textuais: a sequência didática como instrumento de mediação.Tese (Doutorado em Estudos da Linguagem) - Universidade Estadual de Londrina, Centro de Letras e Ciências Humanas, Programa de Pós Graduação em Estudos da Linguagem, Londrina, 2012.

BRASIL. Ministério da Educação e do Desporto/Secretaria de Educação do Ensino Fundamental. Parâmetros curriculares nacionais: língua portuguesa. Brasília, DF: Ministério da Educação, 1997.

BRASIL. Resolução CNE/CP no 2, de $1^{\circ}$ de julho de 2015. Define Diretrizes Curriculares Nacionais para a formação em nível superior (cursos de licenciatura, cursos de formação pedagógica para graduados e cursos de segunda licenciatura) e para a formação continuada. Diário Oficial da União. Brasília, 2 de julho. 2015.

BRASIL. Ministério da Educação. Base Nacional Comum Curricular. Brasília, DF: Ministério da Educação, 2017.

CADILHE, Alexandre Jose; GARCIA-REIS, Andreia Rezende. Letramentos na formação de professores a partir de uma concepção discursiva da linguagem: Reflexões propositivas. In: MAGALHÃES, Tânia Guedes; GARCIA-REIS, Andreia Rezende.; FERREIRA, Helena Maria. (org.). Concepção discursiva de linguagem: ensino e formação docente. Campinas, SP: Pontes Editores, p. 213-231, 2017.

CUNHA, Maria Isabel da. Conta-me agora: as narrativas como alternativas pedagógicas na pesquisa e no ensino. Rev. Fac. Educ. São Paulo, v. 23, n.1-2, p.185-195, jan/dez, 1997. Disponível em: https://doi.org/10.1590/S0102-25551997000100010. Acesso em: 10 mar, 2019.

CLOT, Yves. Vygotski: para além da Psicologia cognitiva. Pro-Posições. v. 17, n. 2 (50) maio/ ago. 2006. 
DUDENEY, Gavin; HOCKLY, Nicky; PEGRUN, Mark. Letramentos digitais. Tradução: Marcos Marcionilo. São Paulo: Parábola editorial, 2016.

ESCREVENDO O FUTURO. Portal Escrevendo o Futuro. Disponível em: https://www.escrevendoofuturo.org.br/. Acesso em: 04 abr. 2019.

GARCIA-REIS, Andreia Rezende; MAGALHÃES, Tânia Guedes. O desenvolvimento profissional docente pelas experiências de escrita do gênero relato. Escrita de docentes em formação: compartilhando saberes em relatos de experiência. 1ed.Campinas: Editora Pontes, 2018, v. 1, p. 15-30.

GARCIA-REIS, Andreia Rezende; COSTA, Míriam Fernanda. Os gêneros textuais em avaliações do ENADE de Letras e em concursos públicos para seleção de professores. Educação em Revista, v.34, p.1-33, 2018. Disponível em: http://dx.doi.org/10.1590/01024698194053. Acesso em: 10 mar, 2019.

GARCIA-REIS, Andreia Rezende. Interação democrática entre professores e pesquisadores da educação. Cadernos para o professor, Juiz de Fora, v. 37, p. 53-64, 2019.

GATTI, Bernadete Angelina. Formação de professores no Brasil: características e problemas. Revista Educação e Sociedade, Campinas, v. 31, n. 113, p. 1355-1379, out./dez, 2010. Disponível em: https://doi.org/10.1590/S0101-73302010000400016. Acesso em: 10 mar, 2019.

KERSCH, Doroteia Frank; MARQUES, Renata Garcia. Hoje me sinto mais confiante com o assunto tecnologia em sala de aula: letramento midiático crítico na formação de professores. In: CADILHE, Alexandre José; GARCIA-REIS, Andreia Rezende; MAGALHÃES, Tânia Guedes. (org.). Formação docente: linguagens, práticas e perspectivas. Campinas, SP: Pontes Editores, p. 85- 109, 2018.

KLEIMAN, Ângela B. Letramento e suas implicações para o ensino de língua materna. Revista Signo. Santa Cruz do Sul, v. 32 n 53, p. 1-25, dez, 2007.

MAGALHÃES, Tânia Guedes; GARCIA-REIS, Andreia Rezende; FERREIRA, Helena Maria. (org.). Concepção discursiva de linguagem: ensino e formação docente. Campinas, SP: Pontes Editores, 2017.

MICARELLO, Hilda. MAGALHÃES, Tânia Guedes. Letramento, linguagem e escolar. Revista Bakhtiniana. São Paulo, p. 150-163, ago./dez, 2014. Disponível em: https://doi.org/10.1590/S2176-45732014000200010. Acesso em: 10 mar, 2019.

NÓVOA, Antônio. Firmar a posição como professor, afirmar a profissão docente. Cadernos de Pesquisa. v. 47 n.166, p.1106-1133 out./dez. 2017. Disponível em https://doi.org/10.1590/198053144843. Acesso em: 10 mar, 2019.

PASSOS, Laurizete Ferragut. Práticas formativas em grupos colaborativos: das ações compartilhadas à concepção. In: ANDRÉ, Marli. (org.). Práticas inovadoras na formação de professores. Campinas, Papirus, 2016. 
PERCURSOS FORMATIVOS. Relatos de prática: Refazendo a travessia. Disponível em: https://www.escrevendoofuturo.org.br/percursos\#/relatos-de-pratica/2176/refazendo-atravessia. Acesso em: 04 abr. 2019.

ROJO, Roxane. Letramentos múltiplos, escola e inclusão social. São Paulo: Parábola, 2009.

SCHLATTER, Margarete. O percurso de escrita do Relato de prática: da experiência vivida à proposta. Na Ponta do Lápis. ano xv n 3, p. [26], jul. 2019. Disponível em:

https://www.escrevendoofuturo.org.br/arquivos/8778/napontadolapis33-28ago2019.pdf.

Acesso em: 20 ago 2019.

SIGNORELLI, Glaucia. O diário de campo como ferramenta de apoio ao processo de aprender a ser professor. In: ANDRÉ, Marli. (org.). Práticas inovadoras na formação de professores. Campinas, Papirus, 2016.

SILVA, Wagner Rodrigues. Letramento científico na formação inicial do professor. Revista Práticas de Linguagem. v. 6, especial, p. 8-23, 2016. Disponível em http://www.ufjf.br/praticasdelinguagem/files/2017/01/2-Artigo-Wagner.pdf. Acesso em: 17 jan, 2017.

STREET, Brian Vincent. Letramentos sociais: abordagens críticas do letramento no desenvolvimento, na etnografia e na educação. Tradução de Marcos Bagno. 1. ed. São Paulo: Parábola Editorial, 2014.

VIGOTSKY, L. S. A construção do pensamento e da linguagem. 2.ed. Tradução de Paulo Bezerra. São Paulo: Martins Fontes, 2010.

Recebido em agosto de 2021.

Aprovado em outubro de 2021. 